\title{
STUDY OF HYDROCARBON MISCIBLE SOLVENT SLUG INJECTION PROCESS FOR IMPROVED RECOVERY OF HEAVY OIL FROM SCHRADER BLUFF POOL, MILNE POINT UNIT, ALASKA
}

Cooperative Agreement. TE-FG22-93BC14864

Petroleum Development Laboratory

University of Alaska Fairbanks

PO Box 755880

Fairbanks, AK 99775-5880

Contract Date: December 1, 1992

Anticipated Completion: June 30, 1996

Total Project Cost:

$\begin{array}{ll}\text { DOE Funding for FY 1994: } & \$ 200,000 \\ \text { Contractor: } & \$ 129,726 \\ \text { Total } & \$ 329,726\end{array}$

Principal Investigator:

G. D. Sharma

Project Manager:

Thomas B. Reid, Bartlesville Project Office

Reporting Period: October 1, 1993 - December 31, 1993

US/DOE Patent Clearance is not required prior to the publication of this document.

\section{OB.JECTIVES:}

The ultimate objective of this three-year research project is to evaluate the performance of the hydrocarbon miscible solvent slug process and to assess the feasibility of this process for improving recovery of heavy oil from Schrader Bluff reservoir. This will be accomplished through measurement of PVT, and fluid properties of Schrader Bluff oil, determination of phase behavior of Schrader Bluff oil solvent finxtives, asphaltene precipitation tests, slim tube dis-

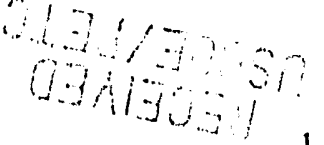


placement tests, core flood experiments and reservoir simulation studies. The expected results from this project include: determination of optimum hydrocarbon solvent composition suitable for hydrocarbon miscible solvent slug displacement process, optimum slug sizes of solvent needed, solvent recovery factor, solvent requirements, extent and timing of solvent recycle, displacement and sweep efficiency to be achieved and oil recovery.

\section{SUMMARY OF TECHNICAL PROGRESS:}

During this quarter, calibration and testing of the miscible coreflood apparatus has been completed. Displacement experiments have been started using this apparatus. Displacement experiments in slim tube have been started to verify the previously conducted slim tube simulation results.

\section{Coreflood Experiments}

An unsteady state waterflood experiment was performed with live Schrader Bluff crude oil. In this experiment, the core holder was packed with Oklahoma No. 1 sand. The porosity and absolute permeability of the core were $33.8 \%$ and 5.1 darcy, respectively. The core was first saturated with water and an initial water saturation was established by displacing the water with live Schrader Bluff crude oil. The oil was then displaced by injecting water at a constant rate of $4 \mathrm{cc} / \mathrm{min}$. Oil production, water production and pressure drop across the core were monitored. Figure 1 shows the oil recovery and water-oil ratio (WOR) as functions of pore volumes of water injected. The breakthrough oil recovery was about $30 \%$, but oil production continued beyond breakthrough and the recovery was $61 \%$ at 1.8 pore volumes injection. Such behavior can be expected when water displaces a high viscosity oil.

\section{Slim Tube Experiments}

The slim tube is composed of a 12-meter section of $6.4 \mathrm{~mm} \mathrm{O.D.} \mathrm{high} \mathrm{pressure} \mathrm{stainless}$ steel tubing which is packed with Ottawa sand and coiled to a diameter of approximately one 
foot. The porosity of slim tube is $35.2 \%$ and permeability was calculated to be 5.0 darcies, using pure toluene as the test fluid of known viscosity. Two runs have been completed during this quarter.

1. $\quad 100 \%$ Kuparuk-Schrader Bluff Gas at 1300 psia and $72^{\circ} \mathrm{F}$

This was the first run conducted in slim-tube apparatus using pure KuparukSchrader Bluff gas as solvent at 1300 psia and $72^{\circ} \mathrm{F}$. This run resulted in recovery of $37.8 \%$ at 1.2 pore volume injection (Figure 2). This shows that, there is no development of miscibility. Also slight glass observations showed two separate phases. Figure 3 shows that solvent break occurred at around $57 \%$ pore volume injection.

2. $100 \%$ Prudhoe Bay Gas at 1300 psia and $72^{\circ} \mathrm{F}$

This run was conducted using 100\% Prudhoe Bay Gas as solvent at 1300 psia and $72^{\circ} \mathrm{F}$. This run resulted in recovery of $45 \%$ at 1.2 pore volume injection (Figure 4). This clearly shows that there is no development of miscibility. Sight glass observations also showed presence of two separate phases. Figure 5 shows that solvent break occurred around 59\% pore volume injection.

\section{FUTURE WORK ! "AN:}

Core flood experiments will continue using live Schrader Bluff oil and miscible solvents. With injection of miscible solvents, effects of slug size and WAG ratio will be examined. Slim tube experiments will also continue with solvents such as $\mathrm{CO}_{2}$ and natural gas with various enrichments with NGL's.

\section{DISCLAIMER}

\footnotetext{
This report was prepared as an account of work sponsored by an agency of the United States Government. Neither the United States Government nor any agency thereof, nor any of their employees, makes any warranty, express or implied, or assumes any legal liability or responsibility for the accuracy, completeness, or usefulness of any information, apparatus, product, or process disclosed, or represents that its use would not infringe privately owned rights. Reference herein to any specific commercial product, process, or service by trade name, trademark, manufacturer, or otherwise does not necessarily constitute or imply its endorsement, recommendation, or favoring by the United States Government or any agency thereof. The views and opinions of authors expressed herein do not necessarily state or reflect those of the United Stales Government or any agency thereof.
} 


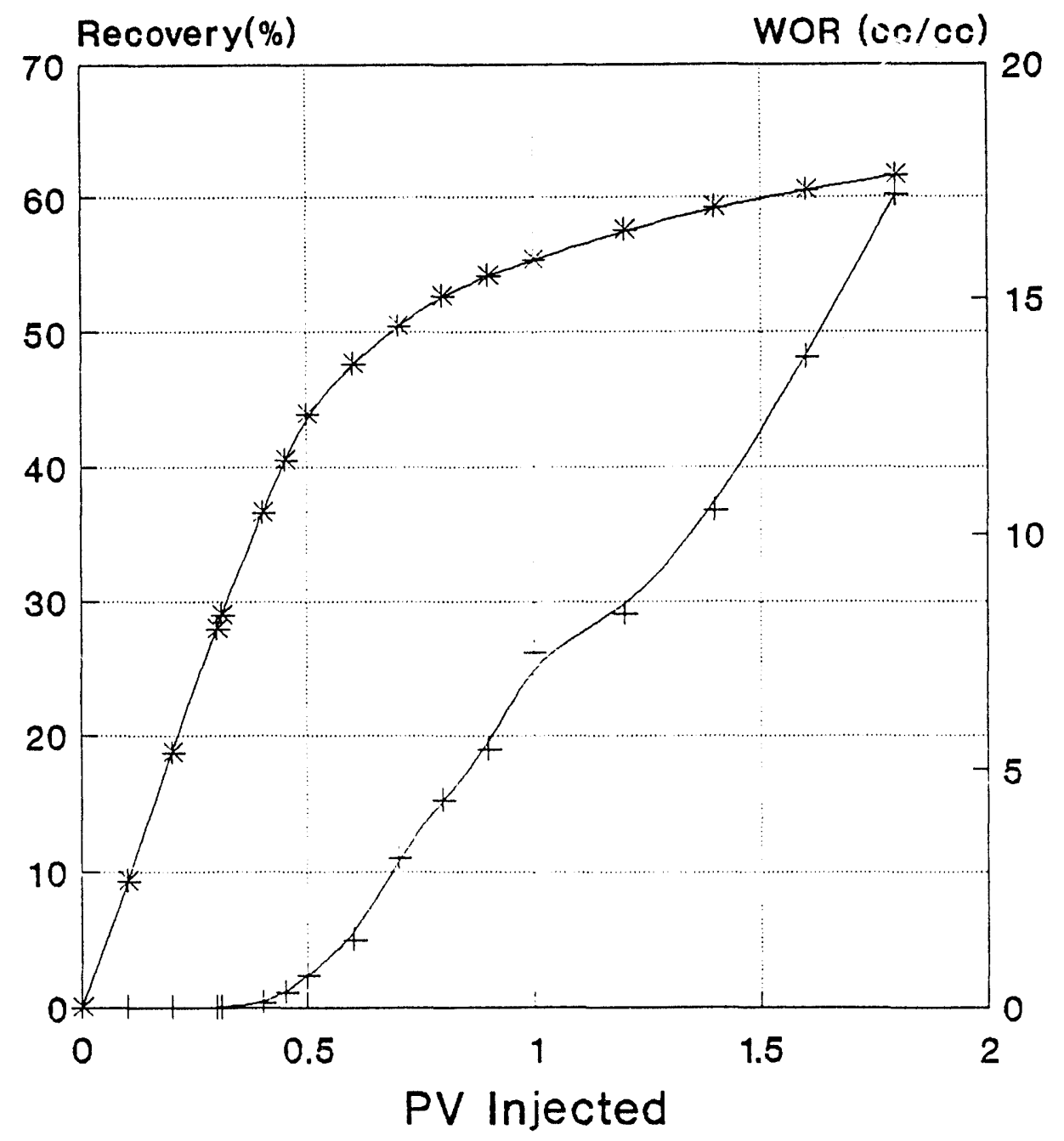

+ WOR $*$ Oil Recovery

Figure 1: Oil Recovery and Water-Oil Ratio for Unsteady State Waterflood Experiment. 


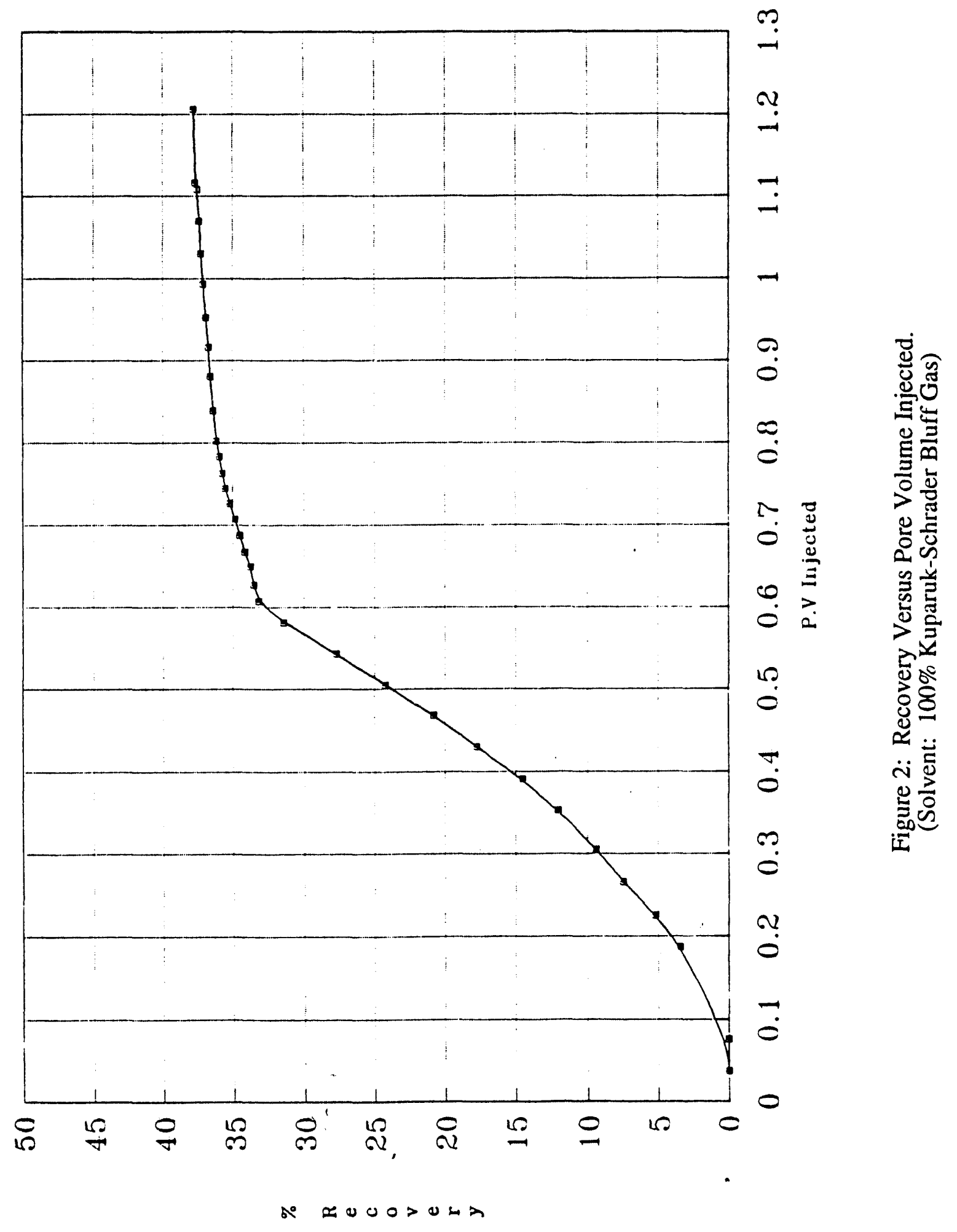




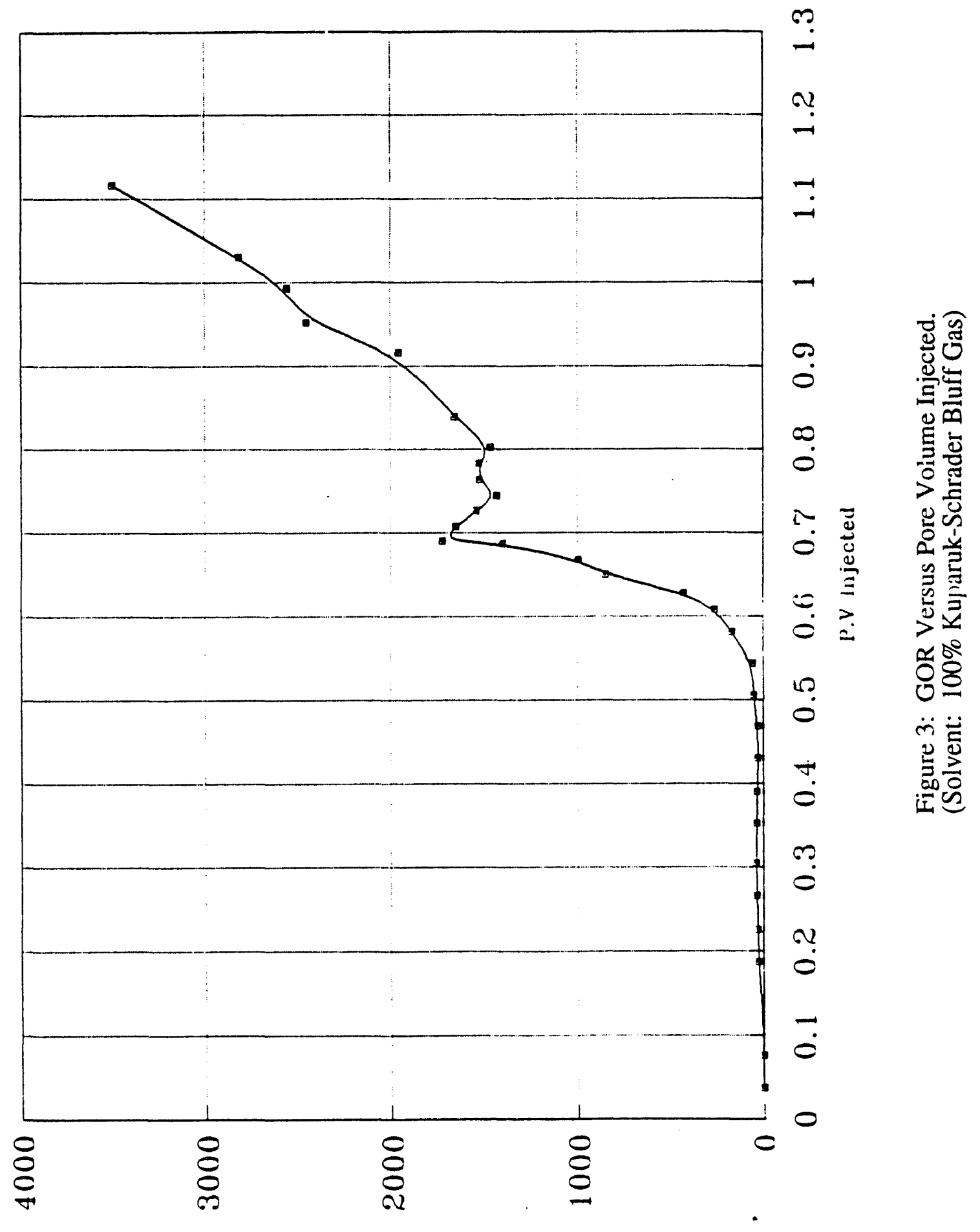

wox 0u>0 


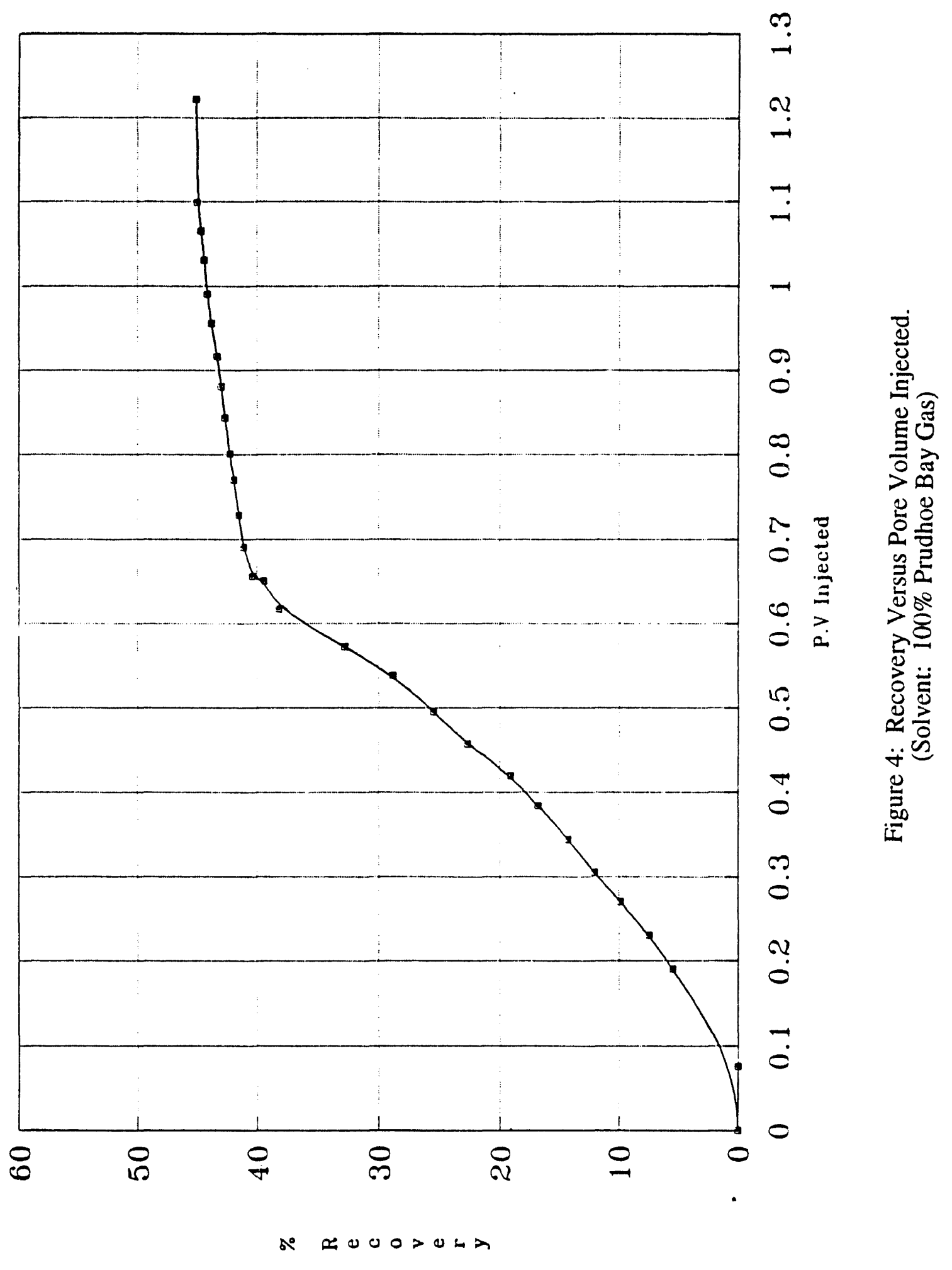


$\infty$

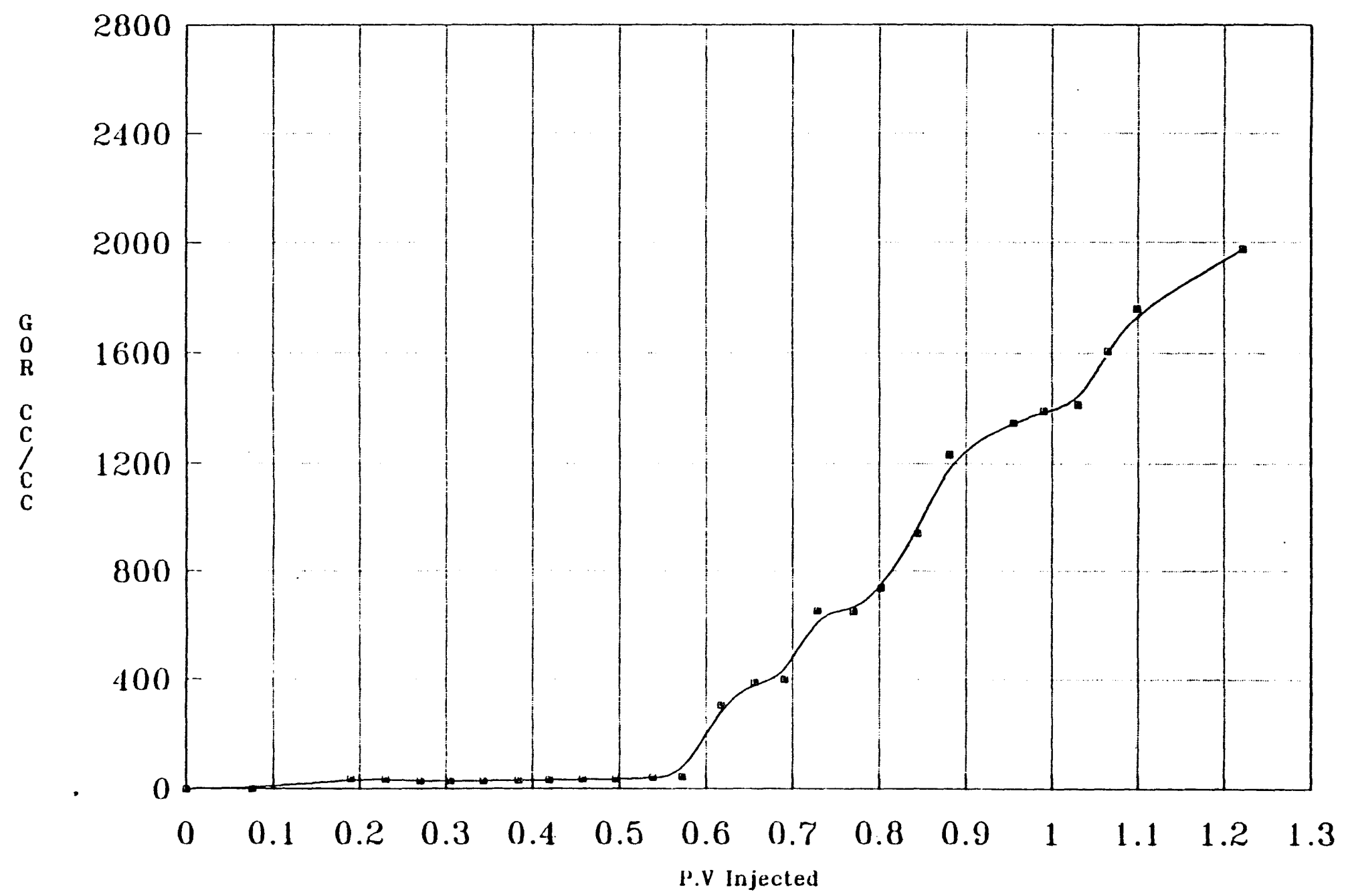

Figure 5: GOR Versus Pore Volume Injected.

(Solvent: $100 \%$ Prudhoe Bay Gas) 


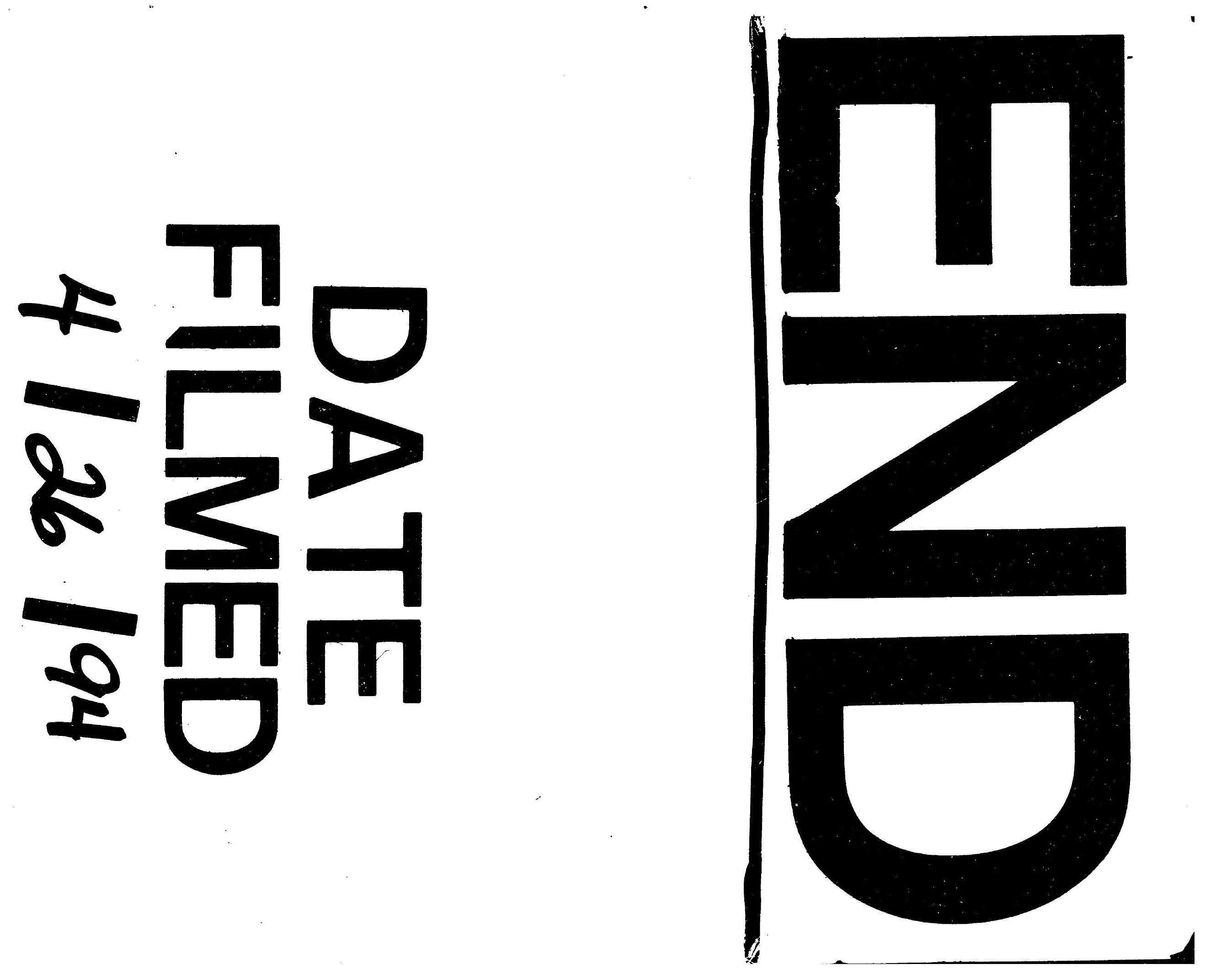


